\title{
ETTORE RECCHI AND ADRIAN FAVELL (EDS) PIONEERS OF EUROPEAN INTEGRATION. CITIZENSHIP AND MOBILITY IN THE EU (CHELTENHAM AND NORTHAMPTON, EDWARD ELGAR PUBLISHING INC., 2009)
}

\author{
Sofia Gaspar \\ Centre for Research and Studies in Sociology \\ Lisbon University Institute \\ Lisbon, Portugal \\ sofia.gaspar@iscte.pt \\ Recibido: 13/5/2010 \\ Aprobado: 4/6/2010
}

Never before has European social integration been one of the foremost topics of discussion in political and civic debates across EU member states. At a time when national and European political representatives are striving to defend economic and financial stability within the Euro-zone, the emergence of a European society in which specific social groups stand out due to their values and social practices becomes crucial. Thus far, the free movement of persons that enables people to move, settle, travel, study, work and retire in any member state is one of the most important principles established by the European Union and it has had a direct impact on citizens' lives. Even though intra-EU mobility is marginal according to official figures (only around 2\% of citizens' move to another EU country), this phenomenon should be taken as the prime indicator of the rise of European citizenship.

This volume edited by Ettore Recchi and Adrian Favell is the final outcome of the PIONEUR project -Pioneers of European Integration 'from below': Mobility and the Emergence of European Identity among National and Foreign 
Citizens in the EU, funded by the European Commission through the Fifth Framework Programme, and involving cross-national research encompassing the five biggest countries of the EU15 (France, Germany, Great Britain, Italy and Spain). The chapters build on the dataset resulting from the project European Internal Movers Social Survey (EIMSS) -, in which 4902 intra-EU migrants who had moved to one of the above countries between 1973 and 2003 were interviewed between 2004 and 2005. The novelty of the selected sampling procedure allowed a comparison of the same migrant groups in different host countries. A questionnaire was developed using new items as well as others from the European Social Survey (ESS) and the Eurobarometer (EB) and it was applied to the overall target population. Questions focused on socio-demographic information, migration history, European and national identity, social integration and political behaviour were included as to examine some major themes in the lives of EU movers.

Pioneers of European Integration is organised in nine chapters that aim to address some of the individual and social consequences in the lives and practices of the EU's intra-mobile citizens. In the first chapter, Recchi and Favell develop a critical overview of some inherent topics to the free movement process (history of free mobility rights, the economic and political rationales underlying this principle, and stocks of mobile citizens in the EU) before presenting a guide to the book. The contents of the subsequent chapters can be divided under two core headings: Chapters 2-4 offer a socio-demographic characterisation of EU mobile citizens, while Chapters 5 to 8 focus on the identities, behaviours and attitudes that distinguish these individuals when compared with EU stayers. Chapter 9 concludes with an analysis of the social and legal barriers that Eastern European movers face in their mobility within the EU in relation to their Western counterparts.

In Chapter 2, Michael Braun and Camelia Arsene start by characterising the socio-demographic background and contextual details of mobile citizens, before presenting a heterogeneous portrait based on age at the time of migration and duration of stay in the destination country. The findings lead to four different clusters of EU movers -'late traditional migrants', 'pure retirement migrants', 'pre-retirement migrants' and 'Eurostars'-. The first cluster includes traditional migrants belonging to classical south-to-north labour flows who moved at the age of 26 years and were settled for about 24 years in their destinations countries; the second refers to northern retired citizens who migrated to the south in search of a better quality of life at the age of 60 years and were living in the host countries for an average of 8 years. Individuals in the third cluster comprehend a recent trend of mobile citizens which involves 
44 year-old movers settled for 13 years whose main motivation was also to improve their quality of life. The last type of mobile EU citizens represents young European professionals who migrated at the age of 28 and were living in the host society for about 8 years.

In line with these four 'ideal types' of movers, in Chapter 3 Oscar Santacreu, Emiliana Baldoni, and Maria Carmen Albert analyse the intrinsic motives for living across national borders, by addressing both the personal and family dimensions supporting that decision. The major outcome of the EIMSS survey is that the affective sphere ('family/love reasons') is the most frequent driver behind moving in Europe nowadays, followed by 'quality of life', jobrelated motives and, lastly, 'study' factors. These findings are in stark contrast with the major motivation for intra-European mobility up till the 1970's work and economic rationales -and demonstrate Europeans' migration patterns have changed mainly by personal and sentimental motivations since that period. This phenomenon reinforces the idea that the intra-EU space is beginning to acquire more internal than international features which might well intensify and widen the European social integration process in the long term.

In Chapter 4 Ettore Recchi compares the EIMSS and ESS datasets so as to assess the inter- and intra-generational social mobility of free movers. This analysis helps clarify whether EU spatial mobility is the pull factor to upward social class movements like in most classical migration projects. Recchi reaches the conclusion that although the intergenerational mobility of movers and stayers is largely the same, lower class citizens take better advantage of their intra-European mobility than their upper-middle class counterparts. Moreover, this phenomenon also reveals some country-origin specificities since citizens who most exhibit upward social mobility normally come from Southern countries like Spain or Italy. In short, despite benefiting those from less privileged social backgrounds, upward social mobility is no greater among intra EU movers than among stayers.

In the next chapter, Antonio Alaminos and Oscar Santacreu concentrate on some central issues related to the social (linguistic competence and social networks) and cultural integration (national orientations and mobility expectations) of EU movers in host societies. Evidence for the social integration index indicates that EU movers master the language of their living country quite well and tend to have more non-national social networks than the natives. On the other hand, cultural integration indicators reveal that although movers are happier than those who stay in their country of origin, they maintain a two-fold wish to either return to their origin countries or keep in the host societies. 
In Chapter 6, Nina Rother and Tina Nebe address national and European identity issues. Since the emergence of a European identity is said to be associated with free movement, the authors draw up a typology based on different combinations of national (country of origin and country of destination) and European identifications. Rother and Nebe conclude that EU movers are more Europeanized than stayers whether or not they present some kind of identity problem ('cognitive dissonance'). Approximately half of the respondents did not reveal any identity conflicts and exhibited tripartite identities (strong affiliations towards the country of origin, country of destination and Europe). It is asserted that these findings suggest that European identity might be an additional neutralising layer which contributes to reducing possible identity tensions between origin and destination cultures.

In the following Chapter, Anne Muxel draws on the political portrait of EU movers. On the whole, discrepancies are found between the values and behaviours of this social group since they are less engaged in national and local political activities than those non-moving citizens, and on the other hand, show a strong interest in the European project and greater participation in EU elections. Moreover, and despite differences in politization levels among countries, leftist inclinations, cultural liberalism and universalistic values are the ideological positions shared by EU free movers.

The media's role in the rise of a European 'public sphere' is another topic that is central to EU social integration. In Chapter 8 Damian Tambini and Nina Rother look at media consumption practices among EU movers, and find that they use transnational and European media whenever possible. Compared to the consumption rates of national stayers, mobile citizens devote more time to internet, television and the press, although this transnational consumption also goes in hand with other sources local media uses. Variables that seem to influence consumption of media from the origin or destination country include having a partner from the host society, age on migration and years of stay in the host country. However, these results do not allow placing EU movers either as consumers of media market from the country origin or destination, since co-national media engagement is the most frequent scenario.

The book ends with a somewhat suggestive theme which calls for further research: are Eastern movers put on the same footing as their Western counterparts? In Chapter 9, Adrian Favell and Tina Nebe advance some interesting results based on a qualitative pilot-study conducted parallel to the EIMSS survey, involving citizens of new member states joining in 2004 (Poland) and in 2007 (Romania). The results of the 40 in-depth interviews show that the spatial trajectories of Eastern EU movers are more similar to classical migration 
experiences than those of Western movers. Eastern citizens refer to suffering from informal discriminatory practices and legal structural barriers when trying to access jobs or everyday services.

Indeed, Pioneers of European Integration provides new and original insights into the values, behaviours, and experiences of mobile citizens by tackling formal and informal barriers that individuals who dared to make active use of their free movement opportunities must still overcome within the EU. The book opens avenues for further reflections that have yet to be empirically sustained or challenged. First of all, one of the most important results unveiled by this data is the leading role played by the affective sphere in EU mobility. Love is therefore an important social trigger for moving and is one of the driving forces behind individual intra-EU migration and the reason for a more permanent stay in a foreign culture. More specifically, nearly 30\% of the respondents of EIMSS reported that sentimental reasons ("living with partner/spouse/children) had led to their move, $61.6 \%$ of whom were married or cohabiting with a native citizen of the destination country. These figures suggest that EU bi-national marriages represent around two thirds of all moves for affective motives. This being the case, these liaisons may create and stimulate different dynamics, strategies and identities within family life that may trigger the enhancement of a European citizenship. As such, parallel to the technocracy of EU institutions, 'love' and 'affection' may be a rising social reality in the coming decades that may, at a private level, help build the roots of a European society 'from below'.

A second issue in need of further study is the meaning of 'self-employment' among these migrants. The evidence provided by Ettore Recchi showed that EU movers are overrepresented in self-employed jobs. This can include both owning a small business and also less well paid situations with some instability and without full entitlement to social security protection, e.g. low-status part-time jobs in the service sector. Even though EU citizens' access to the labour market in other member states is legally more straightforward than that of non-EU migrants, self-employment may be the only way to overcome subtle forms of informal discrimination against people who do not fully master the native language or the social structures of host societies. Self-employment may be the only way some EU migrants can stop being relegated to underprivileged conditions or unemployment in their destination countries. More in-depth qualitative reports are therefore required to examine whether some kinds of working and professional trajectories are linked to social processes that hide invisible discriminatory practices.

A final topic warranting further analysis is the symbolic status associated to specific nationalities and its relation to social integration patterns. In some 
national contexts, European citizens tend to have more symbolic prestige associated with their nationality than non-EU individuals. 'Being European' or 'Western' symbolises belonging to an ethnic group which enjoys positive advantages in an 'ethnic ranking system' and the probability of being subjected to negative social discrimination is therefore lower. This 'positive discrimination' may be transformed into symbolic capital that can act as a powerful tool in developing successful adjustment practices into the receiving country. But is this always so? The findings reported in the book are only restricted to the five largest EU15 countries, but what happens when we compare the integration of 'minor' ethnic nationalities in 'dominant' contexts; or, like Favell and Nebe did, we assess Westerners' moving patterns to those of Easterners? Is the social status associated to the nationality of a Greek or a Bulgarian free mover in Denmark similar to that of a British or a German? Even after controlling for social class' effects, do social images attributed to different EU nationalities determine the level of integration and social opportunities into a host country?

In addition to its undoubtedly original contribution to the understanding of intra-EU migrants, Pioneers of European Integration is a stimulus for research into several issues that help shape a sociology of the European Union. As the editors wish to at the end of the book, only time will ascertain whether these EU pioneers will contribute to a 'better and brighter Europe for all'. 